\title{
Body Image and the Aging Female ${ }^{1}$
}

\author{
Eboni J. Baugh ${ }^{2}$
}

Traditionally, research concerning body image has focused on populations of young women; pre-adolescents, adolescents, and young-adult women. However, current research stresses the increasing importance of examining body image concerns among aging and elderly women.

\section{Body Image and Eating Disorders in Aging Women}

Recent research on older women and body image states that:

- Body image is a life-long concern for women

- Older women view a thinner body as the ideal

- Older women who are overweight are more concerned with weight than peers who are either under-weight or at a healthy weight

- Mood changes can cause body image issues and eating disorder behaviors (e.g., binging and purging)

- Older women are at more risk for the following health problems that could lead to the development of eating disorders:

- Obesity

- Diabetes

- Hormones causing:

- Weight loss or gain

- Muscle loss
- Loose skin

- Thinning hair

- Variations in bone density

- More traumatic events can trigger symptoms:

- Death of a loved one

- Divorce/Separation

- Chronic illnesses

- Older women more often seek help for eating and weight issues

- Higher risk for health problems as a result of eating disorders

- Most who die of anorexia are 65+

\section{Body Image across the Lifespan}

Across the lifespan, women are typically dissatisfied with certain parts of their bodies (i.e., breasts, hips/thighs, buttocks, stomach, etc.), although the levels of satisfaction with these parts vary depending on age. The behaviors that women use to compensate for their dissatisfaction also change with age.

\section{WOMEN UNDER THE AGE OF 30:}

Young women are at most risk for dissatisfaction with their bodies. They are also more likely to engage in compensatory behaviors to lose weight such as dieting, exercise, laxative/ diuretic and supplement use, skipping meals, binging, purging, smoking cigarettes, etc.

1. This document is FCS2299, one of a series of the Family Youth and Community Sciences Department, Florida Cooperative Extension Service, Institute of Food and Agricultural Sciences, University of Florida. Original publication date May 2009. Visit the EDIS website at http://edis.ifas.ufl.edu.

2. Eboni J. Baugh, assistant professor, Department of Family, Youth and Community Sciences, Institute of Food and Agricultural Sciences, University of Florida, Gainesville, FL 32611.

The Institute of Food and Agricultural Sciences (IFAS) is an Equal Opportunity Institution authorized to provide research, educational information and other services

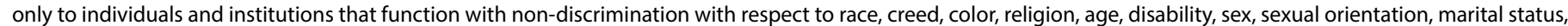

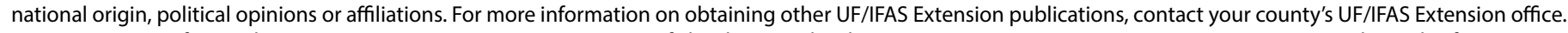
U.S. Department of Agriculture, UF/IFAS Extension Service, University of Florida, IFAS, Florida A \& M University Cooperative Extension Program, and Boards of County Commissioners Cooperating. Nick T. Place, dean for UF/IFAS Extension. 


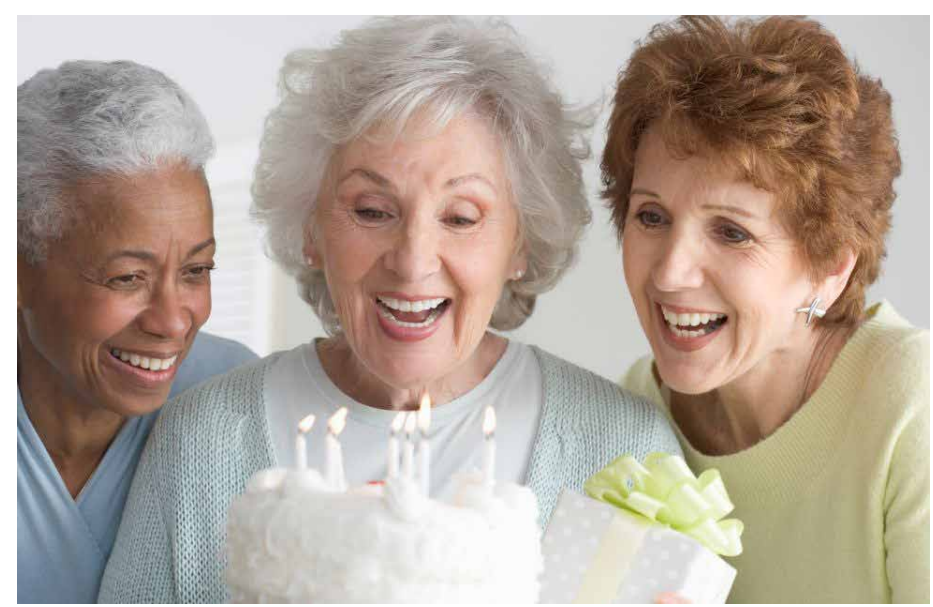

Figure 1.

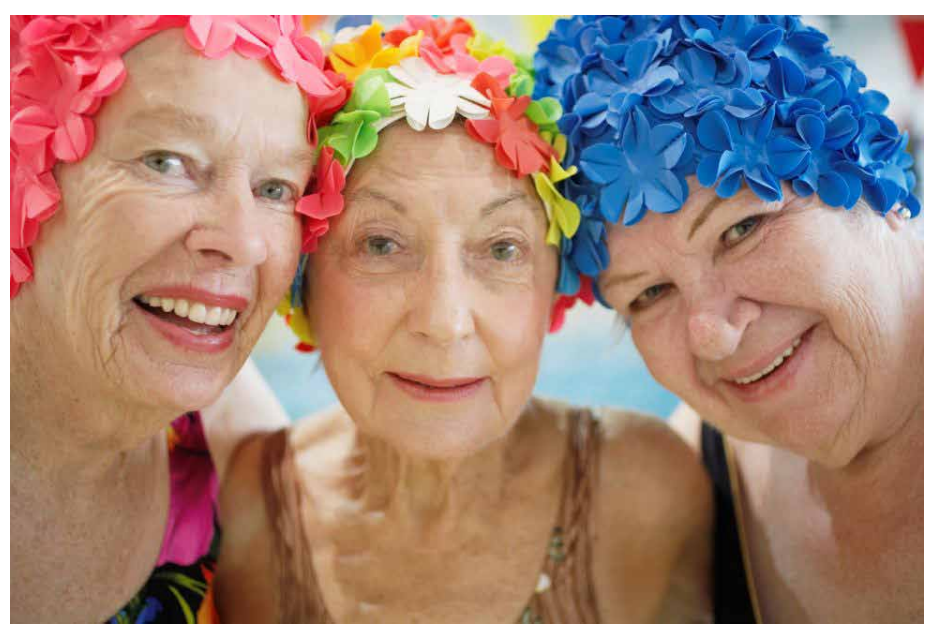

Figure 2 .
Research reports that exposure to and internalization of media ideals in this group causes more dissatisfaction and comparison to others. As a result of the body dissatisfaction and subsequent coping behaviors, young women are also more likely to experience depression, anxiety, and low self-esteem.

\section{AGES 30-65:}

Women in this age group usually have less exposure to the media, and therefore are less susceptible to internalization of the thin ideal. Concerns among this age group focus more on health and well-being, exerting their independence, and career and family goals. That does not mean that this group is exempt from risk. Middle-aged women report societal pressure to conform to certain beauty standards in order to decrease their risk of criticism and disapproval from others. This age group continues the use of weight control behaviors such as dieting, exercising, supplement use, etc.

\section{WOMEN OVER THE AGE OF 65:}

Older women examined in today's research report they still struggle with body dissatisfaction. In fact, women over the age of 65 report similar levels of body dissatisfaction as women under thirty. While older women are less likely to use compensatory behaviors to lose weight, those that do are more likely to experience negative impacts to their health as a result of body image and eating disorders, including:

- Heart disease

- Diabetes

- Bone and muscle loss
- Kidney failure

- Death

\section{'Gerontophobia' vs. Ageism}

Women are consistently judged based on their physical appearance and relationship status, while men are measured more by their accomplishments and wealth. Descriptions of women often include:

"She is so pretty, but why isn't she married?"

"Jamie has lost some weight, she looks good now."

"Sara looks so youthful these days. I wonder what she is using"

Aging women are even more susceptible to these appearance messages from society, which may eventually affect their self-perception. As women age and encounter the normal stages of the aging process, they also become more concerned with comparisons to the ideal thin body type.

Older women confront both personal and societal realities as they age: their own internal fears of their aging bodies (gerontophobia), and the external messages about becoming old (ageism).

Gerontophobia, the fear of old people, the elderly population, or of growing old, causes women to critically analyze their aging bodies. When there is a comparison of an aging body to the young, thin societal ideal, such analysis gives way to diminished self-worth coupled with a high degree of self-loathing. 
Ageism, society's obsession with being young, upholds standards of beauty that are based upon an ideal embodied by media as the young, thin woman who strives for perfection. An aging woman must therefore combat ageism and stereotypes such as "old-maid" or "old hag" as these standards of beauty threaten to marginalize her. Millions of dollars are spent each year on products to enhance youthfulness and beauty.

\section{Implications for Extension}

Extension programs whose primary audience includes aging and/or elderly women should consider the effects of growing older on women's body image and self-perception. Body image information can be incorporated within programming in many areas of Extension: nutrition programs could include information on body image and its affect on obesity, food choice and consumption, and physical activity; family financial management programs with aging women could consider how fixed incomes or budget concerns relate to the desire to purchase diet and beauty products; family relationship programming has the potential to address intergenerational messages transmitted from woman to woman about food and body size.

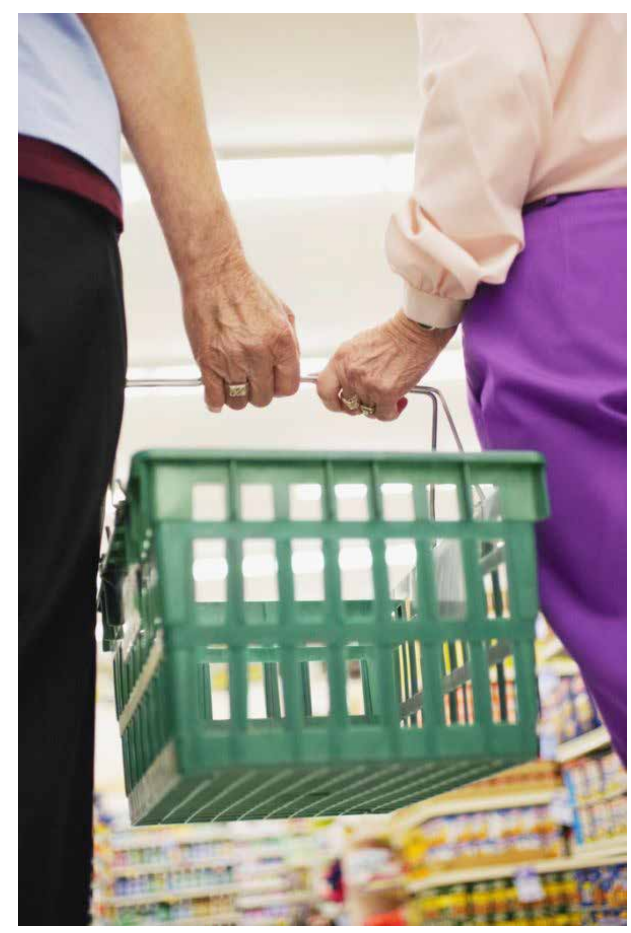

Figure 3.

\section{Tips for Aging Women}

\section{Be Aware of How Dieting Can Affect Body}

- Choose healthy eating
- Refer to food pyramid http://fycs.ifas.ufl.edu/pyramid/

- See a licensed nutritionist

\section{Maintain Contact with Your Doctor}

- Due to health issues when aging, you should remain in contact with your physician

\section{Love Your Body}

- Get moving

- Play at your own activity level

\section{Watch Out for Warning Signs}

- Depression

- Anxiety

- Grief

- Low self-esteem

\section{Online Resources}

American Association for Retired Persons http://www.aarp. org/

Body Image and Aging: Learning to Love the Changes in Love http://www.grandtimes.com/bodyimage.html

National Eating Disorders Association http://www.nationaleatingdisorders.org

\section{Additional EDIS Resources}

Binge Eating Disorder (FCS 8868) http://edis.ifas.ufl.edu/ FY1058

Improving Your Body Image: Tips for Individuals, Families, \& Professionals (FCS 2253) http://edis.ifas.ufl.edu/FY854

Elder Nutrition (FCS 2213) http://edis.ifas.ufl.edu/FY628

Living Actively for Good Health: Older Adults (FCS 8753) http://edis.ifas.ufl.edu/FY554

\section{References}

Bedford, J. L. \& Johnson, S. (2006). Societal influences on body image dissatisfaction in younger and older women. Journal of Women and Aging, 18(1), pp. 41-55.

National Eating Disorders Association. (2006). Health Consequences of Eating Disorders. Retrieved on 26 March 2013 from http://www.nationaleatingdisorders.org/ health-consequences-eating-disorders 
Lewis., D. M. \& Cachelin, F. M. (2001). Body image, body dissatisfaction, and eating attitudes in midlife and elderly women. Eating Disorders, 9 (1), pp. 29-39.

McAlpine, D. (2008). Eating disorders: FAQ on eating disorders in adults. Mayo Clinic, Mayo Foundation for Medical Education and Research. Retrieved on February 24, 2009 from http://www.mayoclinic.com/health/eating-disorders/ HQ00596

Yahnke, R. E. (2004). Women's body image, The Gerontologist, 44(3), pp. 444. 